\title{
Relación Estado-Iglesia y educación en México: vínculos problemáticos entre Estado educador, laicismo y querella escolar
}

\author{
State-Church relationship and education in Mexico: \\ problematic links between education status, secularism and school \\ complaint
}

Laura Rangel Bernal ${ }^{1}$ iD, René Amaro Peñaflores ${ }^{2}$ ii

Universidad Autónoma de Zacatecas-Mexico

Para citaciones: Rangel, L., Amaro, R. (2020). Relación Estado-Iglesia y educación en México: vínculos problemáticos entre Estado educador, laicismo y querella escolar. El taller de la Historia, 12(1), 28-52. DOI: 10.32997/2382-4794-vol.12-num.1-2020-3201

Recibido: marzo de 2020

Aprobado: junio de 2020

Editor: Sergio Paolo Solano. Universidad de Cartagena-Colombia.

Tipología IBN Publindex: Artículo de Investigación

Copyright: $\odot$ 2020. Rangel, L., Amaro, R. Este es un artículo de acceso abierto, distribuido bajo los términos de la licencia https://creativecommons.org/licenses/by-nc-

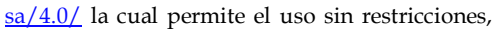
distribución y reproducción en cualquier medio, siempre y cuando que el original, el autor y la fuente sean acreditados.

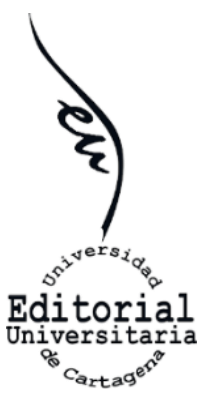

\section{RESUMEN}

En México, la relación entre el Estado y la Iglesia católica ha sido cambiante y compleja. En este artículo sostenemos que más allá del ámbito de la política religiosa, estos cambios han incidido en la educación al asumirse el primero como educador, relevando a la Iglesia en dicho papel, y estableciendo la laicidad como principio rector y fundacional, lo cual incitó una querella por el control educativo. En el devenir de esta relación distinguimos tres tendencias que han marcado al discurso estatal $\mathrm{y}$, consecuentemente, a las políticas educativas oficiales: el radicalismo, el espíritu de conciliación, y el establecimiento de alianzas entre clero y gobierno. A su vez, identificamos tres tendencias en el actuar de la Iglesia respecto de la querella escolar, transitando de la educación pública y la disputa por los libros de texto gratuitos, al interés por la educación privada de élites, y las controversias sobre la educación sexual.

Palabras clave: Historia de la educación; educación y Estado; Iglesia católica; laicidad; laicismo; educación sexual.

\begin{abstract}
In Mexico, the relationship between the State and the Catholic Church has been an ever changing and complex one. In this article, we posit that beyond the realm of religious politics, these changes have influenced education politics giving that the State took over public education in the nineteenth century, relieving the Church from such duties, in addition to the fact that it established secularity as one of its ruling and foundational principles, which incited a dispute over the control of education. In this process, we distinguish three tendencies that mark the State discourse: radicalism, a spirit of conciliation, and the establishment of alliances between clergy and government. In addition, we identify three tendencies in the Catholic Church proceedings that go from trying to recuperate control over public education and the printing of text books, to a notorious interest in private education for the elites, to the controversies surrounding sex education.
\end{abstract}

Keywords: history of education; education and the State; Catholic Church; secularity; laicism; sex education.

\footnotetext{
${ }^{1}$ Doctora en Estudios Socioculturales. Docente investigadora. laura.rangelb@gmail.com

${ }^{2}$ Doctor en Historia. Docente investigador. reneap2002@yahoo.com.mx
} 


\section{INTRODUCCIÓN}

Con la promulgación de las Leyes de Reforma (1855-1863), la relación entre el Estado mexicano y la Iglesia católica cambió radicalmente: de la imbricación y mutua cooperación, se transitó a la separación legal lo que provocó una etapa de confrontación socio-política. En el periodo citado, el Estado trataba de construir plenamente su autonomía y soberanía; la Iglesia, por su parte y con apoyo de la facción conservadora, buscaba independizarse del Estado, pero manteniendo los privilegios corporativos, atribuciones y potestades que reclamaba para sí como derechos pre-jurídicos. El factor cultural que marcó de forma más significativa tal relación fue la secularización social que acompañó a los procesos generales de modernización que empezaba a experimentar la sociedad mexicana del siglo XIX. La secularización comprendió el proceso de diferenciación signado por la separación de los asuntos civiles de los eclesiales y la adopción de la laicidad como principio jurídico que norma y sanciona a la fecha la conformación y funcionamiento de las instituciones estatales.

Si bien la relación Estado-Iglesia se ha orientado por diversos derroteros, uno de los más relevantes, por las implicaciones sociales e ideológicas que ha tenido es el educativo, donde la naturaleza conflictiva de tal relación se ha materializado en la denominada querella por la educación. Como sabemos, la escuela constituye un espacio de contienda ideológica en tanto que es un poderoso agente de socialización "para la formación y el desarrollo futuro de las nuevas generaciones"3 ${ }^{3}$, por tanto, para la construcción de ciudadanía. La educación tiene a la vez la función de reproducir el orden social, así como la de transformarlo según la orientación que se le dé. El control escolar, en términos de la definición de sus enfoques, contenidos y la función principal a desempeñar en una sociedad, figura como elemento central en la contienda ideológica que en esta materia ha revestido la relación entre el Estado y la Iglesia, la cual, es necesario enfatizarlo, no puede describirse en términos simplistas como una confrontación ideológica, sino que ha tenido expresiones complejas con diversos matices, además, sus transformaciones constantes ponen en evidencia los movimientos y variaciones de las posturas ideológicas y de los intereses de ambas partes.

Por lo anterior, afirmamos que el devenir de la relación Estado-Iglesia no sólo incidió en la política en materia religiosa, como sería el caso de la regulación del culto público y de las iglesias, sino que también ha tenido un papel central en la definición y curso de la política educativa en México. En este trabajo nos proponemos indagar la incidencia de dicha relación en la educación a través del análisis de la interrelación que existe entre tres elementos: la conformación del Estado educador, las mutaciones sufridas por el discurso laicista y la querella escolar ${ }^{4}$ en términos del conflicto por el supuesto

\footnotetext{
${ }^{3}$ Caterine Weinamar, et al., Escuela y la educación sexual, Argentina, Manantial/UNFPA, 2008, p. 18

${ }^{4}$ Soledad Loaeza Tovar, Clases medias y política en México: la querella escolar, 1959-1963, México, El Colegio de México, 1988.
} 
"monopolio de la educación", los disensos y las tensiones históricas que se han dado entre Estado e Iglesia por el control educativo y, en consecuencia, por el "control de las conciencias", es decir, por la hegemonía ideológica 5 .

Para ello hacemos una semblanza de la conformación del Estado educador en México desde el siglo XIX con el objeto de recuperar las funciones sociales relevantes asignadas a la educación y los principios que orientaron el desarrollo e implementación de proyectos educativos. En segundo lugar, ofrecemos una revisión del discurso laicista, definido como una línea discursiva que pondera a la laicidad como expresión jurídica de la autonomía y soberanía del Estado frente a cualquier organización eclesial. Esta revisión tiene la finalidad de hacer evidentes las variaciones de tal discurso y explicar sus repercusiones en lo educativo. Sostenemos que hay tres tendencias identificables con momentos de la historia nacional que van de un laicismo radical en apoyo de la secularización, a un laicismo limitado en pro de la conciliación y pacificación del país, para terminar en un abandono del laicismo que algunos autores han interpretado como una "reconfesionalización" del Estado que se observa con mayor énfasis desde inicios del siglo XXI.

Por último, damos cuenta del devenir de la querella escolar cuyos componentes han impactado en la política educativa con resonancias en lo social y lo cultural. Para analizar esta querella nos enfocamos en el actuar de la Iglesia donde también identificamos tres tendencias que dejan ver un desplazamiento estratégico que va del terreno de la educación pública y la oposición a los libros de texto gratuitos, al interés casi exclusivo por la educación privada y la formación de élites, pasando por las controversias en torno a la educación sexual, sus enfoques y contenidos.

En suma, este análisis que forma parte de un trabajo de investigación en curso, pretende contribuir al entendimiento de las relaciones entre el Estado-Iglesia y dar cuenta de cómo dichas relaciones han sido determinantes a lo largo de la historia del México independiente, pues han incidido en la construcción y constante reconfiguración institucional de un lado como del otro, y cuya expresión es visible desde lo político como desde lo educativo.

\section{1.- Conformación del Estado educador}

En el mundo moderno la educación adquiere una dimensión esencialmente social, lo que significa que el Estado no puede deslindarse de ella, por tanto, las acciones en favor de la educación deben estar sometidas a su reglamentación en cuanto a su fomento y observancia. Este planteamiento sobre la obligación del Estado de asumir una función educativa mediante la

\footnotetext{
${ }^{5}$ Por hegemonía ideológica entendemos la lucha social por lograr el poder (dominio-consenso), lo cual implica y significa una reforma intelectual-moral, un "modo de pensar" respecto a ciertas "orientaciones teóricas" y formas específicas de conocer. Y ello es posible sólo a través de la educación y sus contenidos. Luciano Gruppi, El concepto de hegemonía en Gramsci, México, Ediciones de Cultura Popular, 1978, p. 10.
} 
creación de un aparato, la escuela, que regule, administre y promueva la educación pública, aquella dirigida a las masas que por su condición pauperizada no tienen acceso a establecimientos privados, se hace presente en el pensamiento liberal del siglo XIX.

El papel del Estado en la reglamentación e impulso de las tareas educativas se vuelve a tal grado central que, al respecto, señala que ni siquiera es admisible que "la función del educador" pueda ser cumplida por preceptoresmaestros que no posean "garantías especiales", pedagógicas o formativas, que sólo el Estado en turno puede juzgar y sancionar como eficaces o morales ${ }^{6}$. De este modo, en el siglo XIX, los estados-nación se constituyen como instancias que reconocen y legitiman el saber socialmente relevante. En cuanto tales se ocupan por instituir sistemas educativos de corte nacional cuyo objeto es homogeneizar socialmente a la población, formar buenos ciudadanos y forjar identidad nacional ${ }^{7}$.

En el caso mexicano, tras la promulgación de la Constitución de 1857, liberales como Otero, De la Rosa, Ocampo, Prieto, Ramírez, Arriaga, Zarco, Juárez, entre otros, buscaron arrancar el "monopolio espiritual" al clero católico y de esta forma crear la instrucción pública en beneficio del pueblo ${ }^{8}$. De allí que el proyecto liberal triunfante sustentado en el nuevo Estado republicano consistió en fomentar una amplia visión social y en ella "la educación jugaba un elemento constitutivo y definitorio del progreso nacional". Las reformas liberales (Ley Lerdo, Ley Juárez, Ley Iglesias, Leyes de Reforma, etc.), tuvieron como efecto principal la secularización nacional mediante la separación de las instituciones político-civiles respecto a las religiosas, y el establecimiento del Estado laico, es decir, la erección de una estructura político-jurídica-institucional que prescindiera de la tutela moral y el influjo ideológico de cualquier organización religiosa, y cuyo objetivo era "dirigir las conductas, modelar las costumbres, establecer las reglas de juego" respecto a las potestades de cada una de las instituciones que cumplían alguna función social en el territorio mexicano ${ }^{10}$.

Así pues, la educación se convirtió en el "instrumento fundamental que ayudaría a hacer del hombre común, un ciudadano. Más tarde (1889-1891) se le había dado el carácter de base fundamental para la integración de México como nación"11. Es cierto que lo anterior confluyó en un contexto social caracterizado por las carencias económicas y la inestabilidad política a raíz

\footnotetext{
${ }^{6}$ Emile Durkheim, Las reglas del método sociológico, Madrid, Morata, 1974.

${ }^{7}$ Emilio Tenti Fanfani, Sociología de la educación, Buenos Aires, Universidad Nacional de Quilmes, 2004.

Valentina Torres Septién Torres, La educación privada en México, 1903-1976, México: El Colegio de México/Universidad Iberoamericana, 1997, p. 27.

${ }^{8}$ Los liberales impulsaron un conjunto de ideas político-sociales que se formularon como ideología en los años de 1820 1840, en la Constitución de 1857 y en las Leyes de Reforma. Charles A.Hale, La transformación del liberalismo en México a fines del siglo XIX, México, Fondo de Cultura Económica, 2002, p. 15

9 Patricia Ducoing Watty, "Rébsamen: algunas aportaciones conceptuales al proyecto modernizador de la educación en México”, Perfiles Educativos, vol. XXXV, núm. 140, México, 2013, p. 151.

${ }^{10}$ Roberto González Villarreal y Adelina Arredondo López, "1861: la emergencia de la educación laica en México", Historia Caribe, vol. XII, núm. 30, 2017, p. 29.

${ }^{11}$ Josefina Zoraida Vázquez, Nacionalismo y educación en México, México, El Colegio de México, 1970, p. 292.
} 
de las guerras internas y las que hicieron frente a las intervenciones extranjeras:

La escasa población de apenas 8 millones de mexicanos se caracterizaba en su mayoría por ser rústica, pobre, vivir muy dispersa en medio de la insalubridad, enferma, mal alimentada, xenófoba; y si el rosario de males no fuera suficiente, sumida en la ignorancia carente de las luces del alfabeto y de las primeras letras ${ }^{12}$.

A fin de subsanar esta situación, el gobierno juarista procuró impulsar la educación y buscó hacerla universal lo que implicaba que fuera obligatoria y gratuita. Estas disposiciones quedaron asentadas en la Ley Orgánica de Instrucción Pública de 1867, mediante la cual también se establecería la uniformidad de la enseñanza, pues las materias que habrían de impartirse desde el nivel primario hasta el nivel superior, en sus diferentes ramos, pasando por la educación Normal y las artes y oficios, era similar. Asimismo, se ordenaba a las instituciones educativas vigilar su funcionamiento interno a través de reglamentos y reformas. Por ejemplo, dos años después, en 1869, dicha ley sería redondeada añadiéndole a la educación las características de laica, patriótica y científica ${ }^{13}$.

En este sentido, el aspecto central de la ley educativa en la República restaurada fue la aplicación de un criterio científico y de un "método concordante" en el ámbito de la instrucción pública. Así, la educación pasó a ser concebida como una "acción social, planeada, ordenada y cumplida" desde las primeras letras al nivel profesional. Para Juárez y Barreda en ella se cumplían los objetivos de la doctrina liberal: difundir la ilustración en el pueblo como medio "seguro y eficaz" de moralizarlo y de establecer o garantizar la libertad y el respeto a la Constitución de 1857 y sus leyes derivas de ella. Mediante el conocimiento científico-positivista, se reconocería el medio y las bases para "alcanzar las normas de conducta, tanto en el orden personal [individual], como frente a la sociedad"14.

Las bases educativas de corte moderno que establecieron las leyes de $1867 \mathrm{y}$ la reforma de 1869, culminaron en la escuela pública de Joaquín Baranda y Justo Sierra durante el Porfiriato. A finales del siglo XIX y tras los grandes congresos pedagógicos (1889-1890, 1890-1891) se fortaleció la educación moderna en México sustentada en los principios de uniformidad, obligatoriedad, gratuidad y laicidad ${ }^{15}$. Dicha educación no sólo fue el preámbulo de un proceso democratizador de la educación nacional, sino que a partir de él se configuró una "visión utópica", un idealismo pedagógico que reflejaba las esperanzas e ilusiones sobre lo que era posible lograr con la educación de niños, niñas y jóvenes. Tal visión definió el porvenir de la

\footnotetext{
12 Leonel Contreras Betancourt, "Juárez y la instrucción pública al triunfo de los liberales”, Digesto documental de Zacatecas, vol. IV, núm. 7, México, 2006, p. 163.

${ }^{13}$ L. Contreras Betancourt, "“Juárez y la instrucción pública”, p. 163.

${ }^{14}$ José Manuel Villalpando Nava, Historia de la educación en México, México, Porrúa, 2012, p. 214.

${ }^{15}$ Mílada Bazant, Historia de la educación durante el Porfiriato, México, El Colegio de México, 1993, p. 24
} 
educación pública mexicana en el siglo XX, que incluso pervive en nuestros días ${ }^{16}$. En efecto, la resonancia de la utopía educativa alimentó los diversos proyectos educativos revolucionarios.

[...] se puede afirmar que el optimismo, si no es que el idealismo pedagógico del porfiriato se funda en el reconocimiento de que toda persona -incluso el indígena- era educable, y que la educación sería capaz de promover las transformaciones económicas, sociales, políticas y culturales que posibilitarían el acceso a la sociedad moderna ${ }^{17}$.

De esta forma, durante el Porfiriato, a través de las acciones emprendidas por Baranda y Sierra, se desarrolló un pensamiento racional y un lenguaje pedagógico forjado y recuperado de los teóricos nacionales (Carrillo, Ruiz, Torres Quintero, Sierra) y extranjeros (Comenio, Pestalozzi, Rousseau y Fröebel), orientado al desarrollo físico, intelectual y moral del niño, distinguiéndola de la tradicional instrucción que remarcaba más la práctica y, por tanto, se centraba en la figura del docente. La noción de educación moderna adoptada durante este periodo asumió varios significados, unos referentes a las finalidades y funciones de la escuela, y otros a los saberes escolares comprendidos como contenidos únicos y universales; otros más relativos a las modalidades o formas de conducir la enseñanza, particularmente al método; y algunos adicionales relativos al papel del maestro en la educación ${ }^{18}$.

En este marco histórico, con el predominio de la laicidad como principio rector de la educación pública, las relaciones Estado-Iglesia sufrieron cambios. El régimen de separación de ambas instituciones, que funcionaba sobre la base de la supremacía del poder civil sobre el eclesiástico, aunque con reconocimiento jurídico de la Iglesia católica, permitió -a finales del siglo XIX y hasta 1914- que floreciera la práctica pública del catolicismo y la acción social de los creyentes $^{19}$. Al mismo tiempo, la Iglesia Católica experimentó transformaciones ideológicas como respuesta a la "cuestión social”, las cuales se registraron en el tránsito del Syllabus Errorum (1864), que condenaba las prácticas e ideas políticas modernas como el liberalismo, el racionalismo, la democracia y la sujeción del poder eclesiástico al poder civil, a las encíclicas Inmortale Dei (1885) y la Rerum Novarum (1891) que ofrecían la nueva doctrina católica frente al desarrollo capitalista y como alternativa espiritual para reconocer la dignidad social de los sectores populares, en particular a la clase obrera ${ }^{20}$.

Bajo el argumento de la necesidad de pacificación del país y los esfuerzos por evitar más conflictos militares, el porfirismo matizó su postura como Estado

\footnotetext{
${ }^{16}$ P. Ducoing, "Rébsamen: algunas aportaciones conceptuales", p. 153.

${ }^{17}$ P. Ducoing, "Rébsamen: algunas aportaciones conceptuales", p. 153.

${ }^{18}$ P. Ducoing, "Rébsamen: algunas aportaciones conceptuales", p. 153.

${ }^{19}$ R. González y A Arredondo, "1861: la emergencia de la educación laica”, p. 346; Sergio Francisco Rosas Salas, "De la República católica al Estado laico: Iglesia, Estado y secularización en México, 1824-1914”, Lusitania Sacra, núm. 25, 2012, pp.241-247.

${ }^{20}$ R. González y A Arredondo, “1861: la emergencia de la educación laica”, p. 346
} 
laico para presentarlo como neutral, no antirreligioso ni sectario ${ }^{21}$. Así, en 1908, el credo pedagógico de Sierra, proyectó en el niño hábitos y aptitudes para generar en él un "espíritu de iniciativa", mediante una cultura moral, intelectual, física y estética. La educación moral se entendió como "hábitos morales" que los maestros debían enseñar con ejemplos prácticos, no precisamente religiosos. ${ }^{22}$ La moral religiosa que Sierra admitió formaba parte de la libertad individual y de cultos y se circunscribía al seno familiar ${ }^{23}$. Los propósitos de este proyecto eran claros:

La formación moral se laicizó en la medida en que el discurso político la definió como un compromiso con la humanidad y la civilización y, por ende, como un medio republicano para construir un Estado educador. Las aspiraciones de la moral práctica fueron tres: formar hombres virtuosos, padres fuertes e instruidos y buenos ciudadanos ${ }^{24}$.

Tras la Revolución mexicana los caudillos se plantearon dos posturas respecto a la relación Estado-Iglesia, aminorar o suprimir el papel espiritual e ideológico de ésta última o adaptarla-asimilarla a las determinaciones e intereses políticos en turno. Incluso, en 1925, se buscó fundar una Iglesia católica mexicana, no sólo con el objeto de romper los lazos con el Vaticano, sino como una muestra del "reconocimiento de la función social de la religión" 25 . En el debate escolar se impuso la postura de la facción que consideraba que la injerencia de la Iglesia en la educación ocasionaría división en el país pues el clero terminaría por formar una generación de antiliberales $^{26}$, de modo que tras la Revolución se legisló en favor de la laicidad de la educación que se impartiría en los establecimientos públicos "lo mismo que la enseñanza primaria, elemental y superior que se brindaría en los establecimientos particulares". Las restricciones a la participación de la Iglesia quedaron expresadas de la siguiente manera: "ninguna corporación religiosa, ni ministro de algún culto, podrán establecer o dirigir escuelas de instrucción primaria ${ }^{27}$. Los proyectos educativos que surgieron a partir este periodo mantuvieron a la laicidad como principio rector lo cual ha sido un factor importante para el avance de la secularización de la sociedad mexicana.

\footnotetext{
${ }^{21}$ Mílada Bazant, Historia de la educación durante el Porfiriato, México, El Colegio de México, 1993, p. 24.

${ }^{22}$ En este periodo hubo un proceso de secularización peculiar que podemos llamar de transición pues no se eliminaron por completo los elementos religiosos, sino que la enseñanza de la moral se apoyó en ellos. Por ejemplo, los contenidos propuestos por Manuel Santini, pedagogo zacatecano, buscaban fomentar un sentido cívico-patriótico basado en "valores liberales" emanados del Estado de derecho juarista y de los valores católico-universales. ("Boletín de Educación Primaria de 1910", citado por Magallanes, 2016)

${ }_{23}$ M. Bazant, Historia de la educación durante el Porfiriato, 42-60.

${ }^{24}$ María del Refugio Magallanes Delgado, La educación laica en México. La enseñanza de la moral práctica XIX-XX, México, Policromía, 2016, p. 66.

25 S. Loaeza, Clases medias y política en México, p. 184.

${ }^{26}$ Luz Elena Galván, El proyecto de Educación Pública de José Vasconcelos. Una larga labor de intentos reformadores, México, Centro de Investigaciones y Estudios Superiores de Antropología Social, 1982.

${ }^{27}$ Gobierno de México, Constitución Política de los Estado Unidos Mexicanos, México, Diario Oficial de la Nación, 1917.en http://www.ordenjuridico.gob.mx/Constitucion/1917.pdf (consulta: 21 de enero de 2019).
} 


\section{2.- El laicismo y la problemática del discurso laicista}

El término laicismo tienes varias acepciones, algunas de las cuales han sido criticadas por diversos autores. Por ejemplo, se sostiene que la distinción entre laicidad y laicismo es artificial y engañosa pues ha sido usada por actores católicos para "confundir (y dividir) al pensamiento laico" al atribuirle al precepto características anticlericales y antirreligiosas, así como acusar al Estado laico "de promover supuestos desvalores como el relativismo, el nihilismo, la anarquía moral, el libertinaje, el materialismo, etcétera" ${ }^{28}$.

$\mathrm{Si}$ bien es cierto que en el periodo posrevolucionario los gobiernos encabezados por caudillos-militares adoptaron un laicismo combativo que entendía al racionalismo como su expresión más acabada ${ }^{29}$ y que, con base en ello y en las desavenencias que tuvieron con autoridades eclesiales de la época, dicho laicismo se materializó en medidas anticlericales y antirreligiosas, entendemos que esta postura no es un elemento definitorio del concepto de laicismo, sino producto de circunstancias históricas e ideologías específicas.

Con base en este planteamiento y en concordancia con Carlos Pereda ${ }^{30}$, definimos al laicismo como una actitud-postura mediante la cual se actúa en pro del Estado laico y de sus instituciones. Asimismo, entendemos a la laicidad como un acuerdo-arreglo institucional fundamentado en el principio de separación entre el Estado y las iglesias ${ }^{31}$, cuya legitimidad reside en la soberanía popular $^{32}$. La laicidad es una condición para la democracia ${ }^{33}$ y, por tanto, es uno de los pilares que fundan el Estado democrático ${ }^{34}$. De igual modo, concebimos al Estado democrático como garante de derechos, libertades y valores entre los que se encuentran la tolerancia, la pluralidad, la inclusión y la no discriminación. Cabe decir entonces que, la triada laicidad/laicismo/Estado laico, como conceptos ligados inextricablemente a la democracia, no admite posturas o actitudes antirreligiosas ni intolerantes, sino que, al contrario, "solo la proyección institucional del pensamiento laico ofrece las condiciones necesarias para que la pluralidad de ideas, convicciones, creencias, etcétera, conviva pacíficamente y se exprese con libertad"35.

\footnotetext{
${ }^{28}$ Pedro Salazar Ugarte, La laicidad: antídoto contra la discriminación, México, Consejo Nacional para Prevenir la Discriminación, 2007, p. 34.

${ }^{29}$ Carlos Martínez Assad, "Revolución, laicismo y educación”, en Salazar Ugarte, P. y Capdevielle, P. (coords.), Para pensar y entender la laicidad, México, Universidad Autónoma de México/Instituto Federal Electoral/Miguel Ángel Porrúa, 2013, p. 159.

${ }^{30}$ Carlos Pereda, "El laicismo también como actitud", Isonomía, Revista de Teoría y filosofía del Derecho, núm. 24, 2006, p. 16.

${ }^{31}$ Faviola Rivera Castro, "Laicidad y pluralismo", Isonomía. Revista de Teoría y Filosofía del Derecho, núm. 33, 2010, p. 38.

${ }^{32}$ Roberto Blancarte Pimentel, Libertad religiosa, Estado Laico y no discriminación, México, Consejo Nacional para Prevenir la Discriminación, 2008.

${ }^{33}$ Enrique Velasco Ibarra Argüelles, Estado laico mexicano: un ideal deslucido en busca de sentido, México, Instituto de Investigaciones Jurídicas de la Universidad Autónoma de México, 2015, p. 16.

${ }^{34}$ P. Salazar Ugarte, La laicidad: antídoto contra la discriminación, p. 41.

${ }^{35}$ P. Salazar Ugarte, La laicidad: antídoto contra la discriminación, p. 20.
} 
En lo que respecta al Estado educador, el laicismo es una de sus características más relevantes dado el impacto que ha tenido en la configuración del sistema educativo nacional, así como en el cumplimiento de los objetivos de formación de ciudadanos y de integración de la nación. El lugar que ocupa en los análisis sobre la formación y consolidación del Estado educador mexicano también se debe a que las medidas concretas que han derivado de la aplicación del principio de laicidad tales como la exclusión de todo contenido religioso del currículo y la eliminación de la injerencia y atribuciones de las iglesias en materia educativa, han sido fuente de controversias y conflictos desde mediados del siglo XIX.

Tanto el laicismo y el discurso que se ha generado en torno a este concepto ha variado en tanto que han cambiado las ideologías oficiales, los objetivos estatales, así como la postura de los gobiernos con respecto a la Iglesia católica y su papel como actor social. En consecuencia, el discurso laicista, entendido como aquel que pondera la laicidad como expresión jurídica de la autonomía y soberanía del Estado frente a cualquier organización eclesial, ha tenido variaciones notables desde su surgimiento, las cuales han obedecido a la naturaleza compleja y cambiante de las relaciones entre el Estado y la Iglesia, así como a las transformaciones derivadas de los procesos de democratización y secularización que ha experimentado la sociedad mexicana. Estas variaciones han repercutido en el ámbito educativo en la medida en que dicho discurso se ha integrado o, por el contrario, se ha dejado de lado en las políticas escolares.

Como ya señalamos, el surgimiento de este tipo de discurso data del siglo XIX con la necesidad de implementar una educación de corte secularizada y moderna, cuya institucionalización se llevó a cabo tras una lucha intensa entre liberales y conservadores, materializada incluso con cruentos enfrentamientos armados, como al Guerra de Reforma. Pero, a partir de 1867 se establecieron las bases del Estado laico mexicano. Fue en esa coyuntura que desaparece la enseñanza religiosa del currículo oficial. Se conformó un sistema de instrucción ajeno a las doctrinas religiosas y fundamentado en una estructura jurídica, política e institucional que cruzó 1874 (Decreto de laicización de Lerdo de Tejada) y culminó en la legislación educativa de 1891 y $1907^{36}$.

La emergencia de la laicidad educativa fue tanto histórica como conceptual, pues se impuso un dispositivo jurídico-administrativo que consistía en poner en práctica preceptos de gobierno, de régimen político y un modelo de regulación de la instrucción pública. En él, la enseñanza de la moral religiosa sería sustituida por una moral-práctica de corte científica:

¡Una moral sin religión! ¡La formación de ciudadanos de una nación fundada en la soberanía del pueblo, y no la formación de fieles de una

${ }^{36}$ R. González y A. Arredondo, "1861: la emergencia de la educación laica”. 
nación independiente [que] la acompaña un criterio de interpretación presidencial: mientras se dictan las disposiciones sobre religión en las escuelas... primarias públicas no debe exigirse por ningún motivo someter a prácticas religiosas a los alumnos; y respetando el derecho de los padres a definir la educación de sus hijos, solo ellos podrían entregarlos a los ritos y costumbres religiosas de su preferencia ${ }^{37}$.

Desaparecer la enseñanza de la religión en las escuelas como parte de los dispositivos de poder del régimen liberal, mediante las Leyes de Reforma y la separación Estado-Iglesia, significaba poner en marcha una estrategia política articulada por dos elementos: por un lado, la libertad de enseñanza que eliminaba el carácter obligatorio de la instrucción religiosa, y por el otro, el reconocimiento del derecho de los padres de familia de impartir esta educación a sus hijos ${ }^{38}$.

Más tarde, se hicieron presentes posturas más radicales tras defenderse la libertad de enseñanza como fundamento para la secularización de la educación frente al "cáncer de la enseñanza religiosa" y planteaba "la necesidad de estimular la conciencia nacional, objetivo que se impuso incluso a la urgencia de educar espíritus científicos, sobre todo en la medida en que el orden público se convertía en el valor central del porfiriato"39. Así, los esfuerzos por secularizar la educación en México justificaron la activa intervención estatal en la educación pública en favor de la construcción y consolidación del Estado nacional, aun en forma más directa que la prevista por los liberales de la Reforma.

De este modo, la laicidad asumió otras funciones. Es cierto que el proyecto educativo giró en torno a la modernización de la educación, "con la idea de establecer un sistema educativo nacional, federal, uniforme, homogéneo, racional, laico y controlado única y exclusivamente por el Estado"40. Pero aquí el discurso laicista se diluía en el ámbito de lo moderno y los ideales del orden y el progreso. De ahí que en la nueva materia de "Instrucción Moral y Cívica", en la que Justo Sierra sustentó la creación del nuevo hombreciudadano, cuya formación radicaba en tres aspectos prioritarios: el aspecto moral-cívico, el científico y el físico, se cosificará el nuevo discurso laico ${ }^{41}$. En otras palabras, el Estado liberal-oligárquico porfirista asimiló la laicidad al concepto de Estado neutro:

[...] garante de los derechos civiles, previos y separados de toda convicción teológica... [y cuyo] componente clave... [fue] la idea misma de ciudadanía: reconocimiento de la igualdad de todos los ciudadanos ante una autoridad definida como 'Estado de derecho', es

\footnotetext{
${ }^{37}$ R. González y A. Arredondo, “1861: la emergencia de la educación laica”, pp. 43-44.

${ }^{38}$ R. González y A. Arredondo, "1861: la emergencia de la educación laica", p. 44.

${ }^{39} \mathrm{~S}$. Loaeza, Clases medias y política en México, p. 183.

${ }^{40}$ Rosalía Meníndez, "Los proyectos educativos del siglo XIX: México y la construcción de la Nación”, Estudios, vol. X, núm. 101, 2012, p. 199.

${ }^{41}$ R. Meníndez, "Los proyectos educativos del siglo XIX”, pp. 201-202.
} 
decir, sometida a un sistema jurídico considerado neutro desde el punto de vista religioso ${ }^{42}$.

La disputa por la escuela a finales del siglo XIX y principios del XX había cambiado. Se evitaron en la medida de lo posible las confrontaciones como resultado de los esfuerzos gubernamentales para la pacificación del país y la Iglesia desarrolló libremente sus funciones educativas en las escuelas privadas y parroquias como otrora lo había hecho, sin que la leyes que establecían la laicidad educativa obstaculizaran dichas funciones ${ }^{43}$. Simultáneamente, la Iglesia adoptó un discurso más enfocado en la cuestión social, pues a principios del siglo XX, buscó recuperar su papel como "agencia de bienestar social" a través de acciones parroquiales, mutuales y mediante el apoyo de instancias como el Partido Católico Nacional, recién fundado en 1911.

Después de 1900, la vida parroquial colectiva se encontró... ante una renovación teológica conocida como el "Catolicismo Social" y emanada principalmente de las encíclicas de León XIII. Esta nueva teología se constituyó en un movimiento denominado... Acción Social, que se caracterizó por la activa participación de los laicos en los asuntos locales de la Iglesia y un interés acentuado en los curas por involucrase en la vida social de los fieles. Esta renovación, a la vez generacional y teológica, precipitó el declive de la escuela católica liberal, la cual había regido la política episcopal durante el Porfiriato ${ }^{44}$.

\section{3.- Del laicismo radical al laicismo limitado}

Durante el periodo posrevolucionario la Iglesia católica se mantuvo prácticamente incólume sustentada en la legitimidad social con la que había cruzado el siglo XIX, sin embargo, el contenido anticlerical de la Constitución de 1917 (Artículos 3, 5, 13, 27 y 130) que le quitó la personalidad jurídica a cualquier organismo religioso, entre otras medidas, limitó su rango de acción y su injerencia en política y otros asuntos civiles. En vista de ello, el alto clero protestó y apeló a su derecho a la libertad religiosa y, con un "tono conciliador", ofreció cooperar con el gobierno solicitando un "mínimo de tolerancia y respeto mutuo" 45.

A pesar de la oferta cooperativa de la Iglesia el nuevo Estado impuso un laicismo obligatorio y excluyente en la enseñanza primaria. Entre las medidas aplicadas destaca la prohibición de los ministros de culto de dirigir escuelas, aunque se les permitió el ejercicio docente (Art. $3^{\circ}$, Constitución Política, 1917). Igualmente, se implementó un sistema de vigilancia de las escuelas

\footnotetext{
${ }^{42}$ María Teresa Martínez, "Secularización y laicidad: entre las palabras, los contextos y las políticas", Sociedad y Religión, vol. XXI, núm. 36, 2011, p. 72.

${ }^{43}$ S. Loaeza, Clases medias y política en México, p. 183

${ }^{44}$ Robert Curley, "Los laicos, la Democracia Cristiana y la Revolución mexicana, 1911-1926”, Signos Históricos, núm. 7, México, 2001, pp. 151-152.

${ }^{45}$ R. Curley, "Los laicos, la Democracia Cristiana", p. 162.
} 
particulares para buscar asegurar el apego de estos establecimientos a las nuevas disposiciones educativas y "que abarcaba el plan de estudios, los libros de texto (que tenían que ser laicos, aunque no necesariamente los mismos de las escuelas oficiales), los métodos educativos, la escala de calificaciones y el cumplimiento del artículo tercero" 46 .

Aunado a estas medidas se implementaron proyectos educativos de corte radical como fueron la Escuela racionalista, la Escuela rural, y la Escuela socialista, entre cuyos objetivos figuraba sustituir los valores asociados al catolicismo por valores colectivos y una racionalidad orientada por el conocimiento científico. ${ }^{47}$ Este objetivo fue el centro de la disputa por la escuela en tanto que los esfuerzos por la integración de la nación, una vez concluida la lucha armada, se veían afectados por la división ideológica imperante dado que la unidad "resultaba inviable con la contradicción de una Iglesia que pretendía formar a los jóvenes en los principios del conservadurismo, y un Estado que buscaba hacerlo con las bases del liberalismo" $"$.

Si bien estos proyectos obtuvieron algunos resultados positivos, en general fracasaron por una combinación de factores: la falta de formación de docentes en los nuevos modelos pedagógicos, la falta de infraestructura y de otros recursos educativos, así como los excesos de las autoridades civiles que interpretaron el combate a los prejuicios y al dogmatismo mediante la educación, como la erradicación, muchas veces por medios violentos, de toda creencia religiosa; la población, en su mayoría católica, opuso resistencia.

Al alcanzarse cierto grado de estabilidad y paz en el país, la nueva política de reconciliación entre el Estado-Iglesia se consolidó en los años cuarenta. Se trató de un acuerdo tácito de reconocimiento de la labor social eclesiástica, sin menoscabo del estatuto jurídico de la laicidad, la cual, sin embargo, en la práctica se vio limitada. A partir de entonces, las relaciones Estado-Iglesia transitaron por un periodo largo de estabilidad con base en acuerdos parciales y convergencias, que operaron en el margen de la libertad que se concedió a la Iglesia para cumplir funciones sociales propias del modelo de socialización religiosa, eficaz al seno de las escuelas católicas y que fomentaba actitudes conformistas, en concordancia con el control social verticalista y autoritario que había impuesto el régimen posrevolucionario. El acuerdo sobreentendido era el siguiente: "el Estado le permitía a la Iglesia ejercer dentro de ciertos límites su magisterio, a cambio de lo cual la Iglesia contribuía a mantener la disciplina social"49.

\footnotetext{
46 J. Z. Vázquez, Nacionalismo y educación en México, p. 163.

${ }^{47}$ En 1934, mediante una reforma al Artículo $3^{\circ}$, la educación laica quedó subsumida a la educación socialista, sin embargo, se mantuvo la exclusión de toda "doctrina religiosa [y que] combatirá el fanatismo y los prejuicios" mediante "un concepto racional y exacto del universo y de la vida social." (Decreto que reforma al Art. $3^{\circ}$., 1934)

${ }^{48}$ C. Martínez Assad, "Revolución, laicismo y educación”, p. 150.

49 Soledad Loaeza, El fin de la ambigüedad: las relaciones entre la Iglesia y el Estado en México, 19982-1990, México, Instituto de Doctrina Social Cristian, 1990, p. 6.
} 
Después de tres décadas de cooperación, la situación entre los años setenta y, más tarde, los ochenta se complejizó. Por una parte, miembros del clero, grupos de católicos militantes y sectores denominados de derecha política, aglutinados en el Partido Acción Nacional (PAN), enarbolaron la oposición que luchaba por la causa general de la democratización de los procesos electorales y por la alternancia gubernamental, frente a un régimen corporativista articulado por el $\mathrm{PRI}^{50}$. Por otra parte, el alto clero, representado por el episcopado mexicano, estrechó lazos con el gobierno del presidente Miguel de la Madrid (1982-1988) para negociar las modificaciones al Artículo 130 constitucional que otorgarían nuevamente la personalidad jurídica a las iglesias. Estas negociaciones, evidenciaron la cercanía de los nuevos gobiernos denominados neoliberales, con la jerarquía católica y tal fue el signo de los siguientes años.

Las modificaciones finalmente cristalizaron y entraron en vigor durante el mandato de Carlos Salinas (1988-1994), periodo en el que además se reanudaron las relaciones diplomáticas de México con el Vaticano. En este cuadro político y social, en los años noventa se fortaleció, como bandera, la necesidad de una relación más estrecha con la Iglesia Católica. La crisis de credibilidad por el supuesto fraude electoral de 1988 y la visita del Papa, Juan Pablo II, a México en 1990, incidió para que se aceleraran las reformas políticas que otorgarían a las iglesias una mayor participación social, lo cual significaba que éstas se asumieran como aliados políticos y dispositivos de legitimación ideológica del régimen ante el deterioro del consenso como resultado del alto costo social generado por el proyecto de modernización e integración del país a la economía neoliberal.

A través de estas reformas el Estado posibilitó una mayor injerencia del clero en la sociedad: se reconoce [la] personalidad jurídica a [las] iglesias y agrupaciones religiosas, desaparece la prohibición de intervenir directamente en la educación, los ministros de culto tendrán derecho a votar como ciudadanos, aunque no podrán asociarse con fines políticos ni realizar proselitismo a partidos o asociaciones políticas; podrán adquirir poseer y administrar los bienes indispensables para sus fines y se otorga mayor flexibilidad para las celebraciones y manifestaciones de culto externo ${ }^{51}$.

\section{4.- Abandono del laicismo}

La relación entre el Estado y la Iglesia católica a inicios del siglo XXI parecía cada vez más cercana en tanto que la derecha, representada por el PAN, desbancó al PRI en las elecciones federales del año 2000, lo que dio paso a un episodio de alternancia política por primera vez en 71 años. Dicha cercanía

\footnotetext{
${ }^{50}$ Soledad Loaeza, "La Iglesia y la educación en México. Una historia en episodios”, en Pilar Gonzalbo Aizpuru (coord.), Historia y Nación I. Historia de la educación y enseñanza de la historia, México, El Colegio de México, 1998, p. 185.

${ }^{51}$ María Concepción Mejía Piñeros, "Cambios recientes en las relaciones Iglesia- Estado en México y su impacto en los derechos de las mujeres", en "XX Congreso Internacional de la Latinamerican Studies Association”, Guadalajara, 16-20 de abril de 1997, p. 3.
} 
y la notoria afinidad se hizo más patente en el gobierno de Vicente Fox. Por ejemplo, mediante una carta que envió a la Conferencia del Episcopado Mexicano en abril del 2000 aseguraba a dicha instancia que durante su mandato promovería diversas causas directamente vinculadas con los intereses de la Iglesia católica: "el respeto al derecho a la vida desde el momento de la concepción hasta el momento de la muerte natural", "el libre acceso para asistencia espiritual y religiosa en los centros de salud, penitenciarios y asistenciales", eliminar restricciones a la libertad religiosa (entiéndase aquellas que limitaban la participación política de organizaciones religiosas y ministros de culto), exenciones fiscales, abrirle a las iglesias el acceso a los medios de comunicación, y "respetar el derecho de padres de familia a decidir sobre la educación de sus hijos" 52 .

Durante el gobierno de Felipe Calderón (2006-2012), el laicismo siguió perdiendo terreno y, desde el nivel federal, se pretendió orientar las políticas públicas siguiendo la línea de la agenda católica. Un caso muy sonado fue el de José Ángel Córdova, secretario de salud, quien intentó alinear la política nacional sanitaria con la política sexual del Vaticano y, de paso, modificar los planes y programas escolares públicos, lo cual comprometería su carácter laico. En una entrevista concedida a un periódico en 2007 , el funcionario descalificó las campañas de prevención del VIH-Sida realizadas en el sexenio anterior por la promoción "abierta" del uso del condón como principal forma de prevenir su contagio y afirmó que, en su lugar, debía "privilegiarse la educación sexual a cargo de los 'padres de familia' y promover la abstinencia y la fidelidad conyugal"53.

En concordancia con los gobiernos anteriores, durante el sexenio de Enrique Peña Nieto, el Estado y la Iglesia se mantuvieron cercanos. Lo demuestran los numerosos episodios en los que políticos trataron de ampararse de diversas formas bajo la legitimidad social de figuras religiosas para tratar recuperar la que sus gobiernos habían perdido. Este tipo de tácticas confirman el peso creciente que ha tenido la Iglesia Católica en el escenario político nacional desde la década de 1960, cuya influencia se acentúo a partir de 1980 "en coincidencia con el deterioro de la economía del país y la erosión de la legitimidad del sistema político" $"$.

Lo que se observa en el periodo 2000-2018 es una actitud displicente hacia el laicismo y lo que representa para el mantenimiento del Estado laico. Por ello, Bernardo Barranco afirma que este contexto de notorio abandono del discurso laicista, junto con la no aplicación o modificación de las leyes que restringen la participación política de las organizaciones religiosas, se remite a una

\footnotetext{
52 Leonardo Natividad Rueda, Leonardo Natividad Rueda, Las relaciones Estado-Iglesia(s) en México, 2000-2013: construcción de la agenda política, México, Movimiento Ciudadano, 2015, pp. 250-251.

53 Grupo de Información en Reproducción Elegida, "En salud, el oscurantismo mata", 2007, en http://repositorio.gire.org.mx/handle/123456789/1841 (consulta: 10 de febrero de 2019).

${ }^{54}$ M. Mejía, "Cambios recientes en las relaciones Iglesia- Estado", p. 12
} 
especie de 'reconfecionalización' de lo político, desde donde el presidente y la clase política guardan un trato especial con la Iglesia católica ${ }^{55}$.

Para recapitular, en el asunto de las relaciones entre Estado e Iglesia, su repercusión en el discurso estatal y su impacto en las políticas educativas, es necesario resaltar que históricamente han existido "contradicciones que muestran la ausencia de una política clara y consistente" del Estado hacia la Iglesia Católica ${ }^{56}$. Sin embargo, se pueden distinguir tres tendencias: primeramente, un laicismo radical manifiesto tanto en el periodo de la Reforma como en el revolucionario y posrevolucionario. Luego, un laicismo limitado, es decir, presente en las leyes e invocado en el discurso, pero no llevado a la práctica, el cual es evidente durante el Porfiriato, en la década de 1940, hasta finales del siglo XX. Por último, observamos un abandono del discurso laico y el surgimiento de un cuasi confesionalismo con los gobiernos de derecha a inicios del siglo XXI. Estas tendencias dejan ver una relación cambiante y compleja entre el Estado mexicano y la Iglesia Católica y que va más allá de lo que señalan las leyes y lo que plantean los discursos, cuyo impacto es notable en curso de la educación en México, por ello enfatizamos la relevancia de integrar este factor a los próximos estudios que aborden este tema.

\section{5.- El devenir de la querella: entre la educación pública y la privada}

La historiografía educativa decimonónica ha destacado el carácter tenso de la relación Iglesia-Estado durante la segunda mitad del siglo XIX, lo cual se acentuó luego de que se sancionara la libertad de enseñanza (Artículo $3^{\circ}$. Constitución de 1857), e inevitablemente desembocó en uno de los conflictos más profundos, manifiestos y latentes, de la historia política mexicana: la disputa por la escuela. Para Soledad Loaeza $(1988)^{57}$, en el centro de la querella escolar se localiza un conflicto de carácter ideológico que se enfoca en el control de las instituciones educativas a fin de alcanzar o, en su caso, mantener la hegemonía cultural que se materializa en los preceptos de educación obligatoria, gratuita y laica, que otorga el Estado mexicano frente a una educación fundada en principios religiosos, impartida por instancias eclesiales y acorde con los ordenamientos del Vaticano.

Desde este punto de vista, la querella escolar es resultado de la confluencia de varios procesos que es necesario examinar. Por una parte, la secularización de la sociedad como proceso sociocultural, devino en un resultado jurídicopolítico, es decir, en un proceso de laicización institucional que permitió la formación de un Estado laico. Por otro lado, se transitó de la libertad de enseñanza como un elemento transformador de nuevos valores, a la

\footnotetext{
55 Bernardo Barranco, "La clase política mexicana una amenaza para la laicidad", Blog Cuaderno de bitácora, 2015, en https://bernardobarranco.wordpress.com/2015/11/19/la-clase-politica-mexicana-una-amenaza-para-la-laicidad/ (consulta: 2 de marzo de 2019).

${ }^{56}$ M. Mejía, "Cambios recientes en las relaciones Iglesia- Estado en México", p. 9

${ }^{57}$ S. Loaeza, Clases medias y política en México.
} 
prohibición de la enseñanza pública de contenidos religiosos, proceso que culminó en 1874.

En cuanto a los argumentos en torno a quién correspondía el control la educación, han prevalecido dos: por una parte, el eclesial o "derecho natural" en favor de la instrucción religiosa para todos los sectores y, por la otra, el argumento liberal en pro de la educación pública laica, como como instrumento jurídico de convivencia social. La Iglesia mantiene la idea de que la educación debe impartirse en la familia y apegarse estrictamente a las creencias religiosas, las cuales en México se identifican primordialmente con el catolicismo. De igual modo, el clero que dirige esta instancia, reclama un papel preponderante en la impartición de la educación con base precisamente en el concepto de derecho natural, es decir, anterior e independiente a las convenciones, leyes civiles e instituciones sociales fundadas por el derecho positivo, que otorgaría a la Iglesia una posición especial respecto del Estado moderno. En este sentido, la Iglesia defiende la educación como un "derecho natural que exige que la persona siga el 'dictamen de su conciencia, sin constreñirse por nada ni nadie"" 58 . El objetivo central de la educación consistiría en la formación espiritual y moral de las personas con apego a la doctrina cristiana que, se asume, debe ser impartida a la población en edad escolar en los planteles educativos ex profeso.

Por su parte, los liberales desde el siglo XIX han defendido la necesidad de separar a la Iglesia de la función educativa para que el Estado la asuma enteramente, lo cual implicaba, reafirmamos, la laicización de la educación. Es necesario enfatizar que históricamente la laicidad de la educación se planteó no sólo como un asunto educativo, sino fundamentalmente como problema político, en tanto que, la instrucción del pueblo planteaba un problema para la construcción de la unidad e identidad nacional ${ }^{59}$.

Por ello no es extraño que en los albores del siglo XX y en el marco del Congreso Científico Nacional (1897), se alzaran voces conservadoras emitiendo fuertes críticas contra el Estado educador: denunciaban el fracaso de la escuela pública laica y calificaban como necesario y urgente el "regreso de las escuelas confesionales para subsanar una serie de problemas sociales como el analfabetismo y la ausencia de una enseñanza moral capaz de normar los comportamientos antisociales" ${ }^{60}$. Ante el planteamiento de sí se debía incluir la moral religiosa a la instrucción pública, las disposiciones legales impedían esta posibilidad y se planteaba que la única moral que tenía cabida en la escuela pública sería la "razonada o científica". Dicho razonamiento permitió que "el Estado se arrogara el derecho de enseñar moral laica en las

\footnotetext{
${ }^{58}$ S. Loaeza, "La Iglesia y la educación en México", pp. 186-187

${ }^{59}$ Charles A.Hale, El liberalismo mexicano en la época de Mora (1821-1853). México, Siglo XXI Editores, 1972, p. 176; Luz Elena Galván, El proyecto de Educación Pública de José Vasconcelos. Una larga labor de intentos reformadores, México, Centro de Investigaciones y Estudios Superiores de Antropología Social, 1982, p. 10.

${ }^{60}$ María del Refugio Magallanes Delgado, La educación laica en México. La enseñanza de la moral práctica XIX-XX, México, Policromía, 2016, p. 28.
} 
escuelas, si bien la familia conservaba el derecho de inculcar otro tipo de principios morales" $"$.

Entonces, a lo largo del siglo XIX e inicios del siglo XX los argumentos liberales se impusieron y se consolidó la educación laica. Empero, lo anterior generó la necesidad de plantear una nueva estrategia que llevara a los grupos de derecha a preservar la educación de las élites como su "zona de exclusividad" donde "necesariamente, la instrucción religiosa ha de garantizar la unión del compromiso ideológico con las ventajas sociales" 62 .

Más adelante, las circunstancias históricas que rodearon a la Guerra Cristera (1926-1929) provocaron nuevos cambios en las relaciones Estado-Iglesia: después de un periodo de intensa violencia y radicalización de ambas partes, se estabilizaron las desavenencias. ${ }^{63}$ Para la década de 1940, el repliegue de la Iglesia a la educación privada dirigida a la formación de las élites, con miras a incidir indirectamente en la esfera política, es notable. Este repliegue estuvo acompañado de una campaña de desprestigio a la educación pública tachándosele de deficiente e incapaz de alcanzar los niveles de calidad que ostentaba la educación privada. La campaña también evidenciaba el desprecio de las élites y de la cúpula de la jerarquía católica hacia las clases populares, puesto que la educación pública y gratuita era la única educación a la que tenía acceso la población pauperizada ${ }^{64}$.

Cabe señalar que, si bien fue notorio el movimiento hacia la educación privada, la Iglesia no abandonó del todo el terreno de la educación pública, pues en forma paralela, a nivel internacional, la cúpula eclesial reclamaba su derecho a ejercer la función educativa sin impedimentos estatales por vías como el Concilio Vaticano II (1959-1962), la Declaración del Concilio y la Declaración Universal de los Derechos del Hombre de 1948. Sobre la base de este reclamo se encontraba el planteamiento de la superioridad del orden natural, esto es, divino, sobre el orden temporal, al tiempo que exigía el reconocimiento de la primacía de la familia frente al Estado en el ámbito educativo, lo cual colocaba al Estado y a la educación que éste ofrecía en una posición subsidiaria ${ }^{65}$.

Para finales de la década de 1950, la querella escolar regresó al ámbito público con la oposición a los libros de texto gratuitos que se distribuyeron

\footnotetext{
${ }^{61}$ M. Magallanes, La educación laica en México, p. 29

${ }^{62}$ Carlos Monsiváis, El Estado laico y sus malquerientes, México, Universidad Autónoma de México/Random House Mondadori, 2008, p. 115.

${ }^{63}$ La Ley Orgánica de Educación Pública (1942) fue uno de los instrumentos que ayudó a conciliar las desavenencias entre el Estado-Iglesia en materia educativa, en tanto que se mantenía la exclusión de "toda enseñanza o propaganda de cualquier credo religioso" (Artículo 16, Fracción IV) y el de combatir "el fanatismo y los prejuicios, ajustando las enseñanzas a los métodos que informen el conocimiento científico". (Artículo 16, Fracción V). Pero también consignaba que "no podrá entenderse legalmente por fanatismo y prejuicios, la profesión de credos religiosos y la práctica de ceremonias, devociones o actos de culto respectivo, realizados conforme a la ley" (Artículo 17). Esta disposición impedía a los educadores "atacar creencias o prácticas religiosas lícitas de los educandos". (Artículo 17). Esta ley trató "de mantener la hegemonía del Estado sobre el clero, pero dentro de un clima de conciliación de intereses". Guillermo Villaseñor, Estado e Iglesia: el caso de la educación, México, EDICOL, 1978, p. 175.

${ }^{64} \mathrm{C}$. Monsiváis, El Estado laico y sus malquerientes.

${ }^{65}$ S. Loaeza, "La Iglesia y la educación en México", p. 186.
} 
en escuelas primarias en el sexenio de Adolfo López Mateos (1958-1964). El objetivo de producir y circular estos libros era homogenizar contenidos y llegar a un mayor número de estudiantes con el objeto de fortalecer la unidad nacional y avanzar en la modernización de la sociedad mexicana. La inconformidad provino de diferentes sectores que supuestamente vieron afectados sus intereses particulares. Por una parte, las empresas editoriales se quejaban de perder el negocio de la venta de libros; por la otra, la oposición católica calificaba a estos libros de antijurídicos, antidemocráticos y antipedagógicos "puesto que convertía[n] al maestro en 'un repetidor mecánico" "66. Asimismo, se consideraba su obligatoriedad como una imposición que evidenciaba la naturaleza autoritaria del Estado.

Este nuevo bastión de la querella escolar posibilitó la articulación de los grupos de clase media, de la elite y de las clases populares para dar cauce a protestas contra un régimen político basado en un modelo económico desarrollista que ahogaba los mecanismos democráticos y de participación política. La crisis de participación (1957-1963) se trasladó al ámbito del Estado educador, cuyas dimensiones adquirieron un carácter nacional, pues la ofensiva encontró un amplio eco social ${ }^{67}$.

Los libros de textos gratuitos fueron rechazados, no obstante que no contenían cambio ideológico alguno. Lo que se impuso fue más bien una oposición que cobró relevancia en el contexto internacional configurado por el periodo de la posguerra, la Guerra Fría, el marcartismo norteamericano, acentuadamente anticomunista o antiprogresista y, finalmente, por el triunfo de la revolución cubana. Este ambiente político se convirtió en caldo de cultivo de una coyuntura muy bien aprovechada por los grupos de oposición que veía a los libros de texto como instrumentos de "ideologización socialista-comunista" y, por ende, anticatólica.

En las décadas siguientes se mantuvo el conflicto por la hegemonía ideológica y cultural, ahora entendida como defensa de la libertad de impartir enseñanza religiosa y cuyo "pretexto instrumental" lo representó la querella escolar utilizada eficazmente por los grupos tradicionales como la Iglesia, el PAN, la Unión Nacional Sinarquista y el Movimiento Familiar Cristiano, los cuales tras el debate sobre los contenidos de enseñanza, en realidad buscaron fortalecer su posición política en la estructura de poder. Para la Iglesia católica el conflicto le significó una nueva oportunidad de crecer en el escenario político nacional, aunque debe destacarse que cobró mayor fuerza dicho posicionamiento en los años ochenta, en el contexto de la crisis económica y la pérdida de legitimidad del sistema político neoliberalcorporativo.

\footnotetext{
${ }^{66}$ V. Torres Septién, La educación privada en México, 1903-1976, pp. 69, 70.

${ }^{67}$ S. Loaeza, Clases medias y política en México, p. 185.
} 
Para finales de la década de 1980, ante las crecientes demandas sociales a raíz del deterioro de las condiciones de vida de las mayorías, la necesidad de democratización y el reclamo de participación de nuevos organismos de la sociedad civil, se plantearon cambios constitucionales respecto a las relaciones Estado-Iglesia. Hechas las reformas a los Artículos $3^{\circ}$ y 130 constitucionales, desapareció la prohibición a ministros de culto de impartir educación. Así, el clero incursionaba más abiertamente en el ámbito educativo, además de que se atendían las voces que pugnaban, desde la década de 1950, por el establecimiento de más escuelas privadas (católicas), principalmente en el nivel primario, para satisfacer la demanda que el Estado no podía cubrir.

\section{6.- La querella por la educación sexual}

La enseñanza de contenidos de aprendizajes sobre sexualidad humana ha sido uno de los puntos nodales de la querella educativa. Fue 1932 cuando por primera vez se habló de la propuesta de educación sexual dirigida a estudiantes de primaria de la Ciudad de México, lo que causó una polémica rara vez vista hasta entonces. A finales del siglo XX y principios del siglo XXI la relevancia de dicho punto del conflicto se ha acentuado. Lo anterior se debe a que el proceso cultural de secularización que ha experimentado la sociedad mexicana, así como a los cambios respecto al orden socio-sexual tradicional entre los que se encuentran el reconocimiento de los derechos sexuales y reproductivos de mujeres y minorías sexuales, la participación de las mujeres en el ámbito laboral y profesional, la reconfiguración de roles de género, la creciente separación entre la sexualidad y reproducción propiciada por el introducción y uso casi generalizado de métodos anticonceptivos, entre otros fenómenos, han generado la reactivación de la militancia católica que sigue los lineamientos conservadores en materia de política sexual establecidos por el Vaticano, los cuales están orientados a revertir estos fenómenos y su impacto sociocultural.

Si bien en décadas anteriores la Iglesia condenaba la educación sexual dirigida a menores de edad, su actitud actual es en favor de su impartición, siempre y cuando ésta se apegue a los principios doctrinales católicos. Para justificar esta postura nuevamente se recurre al argumento del derecho natural que implica el principio de subsidiariedad, cuya función es garantizar un cierto grado de independencia de una autoridad inferior respecto de una instancia superior: un poder local respecto de un poder central. Es el reparto de las competencias equitativas entre los diferentes niveles de poder sustentado en la base institucional de los Estados federales y de la política en general ${ }^{68}$. Así, el argumento del "derecho natural" de los padres y madres para educar a sus vástagos de acuerdo con su fe religiosa, colocaba a la escuela en una posición subsidiaria. Para las autoridades del Vaticano esto incluía "el

${ }^{68}$ Roberta Panizza, "El principio de subsidiariedad", 2018, en www.europarl.europa.eu/ftu/pdf/es/FTU_1.2.2.pdf (consulta: 18 de febrero 2019). 
derecho de los padres a que sus hijos no sean obligados a asistir a cursos en la escuela en estas áreas, que no estén en armonía con sus convicciones morales o religiosas" 69 . De ahí abrevaban los grupos conservadores para justificar su oposición a la educación sexual laica.

Para la década de 1990, la identidad de intereses entre la Iglesia y el PAN posibilitó que en la plataforma política de este partido se enarbolaran demandas como la reforma al Artículo $3^{\circ}$. constitucional cuya finalidad era romper con el monopolio estatal educativo, suprimir el laicismo obligatorio y abrir totalmente la puerta a la participación de la Iglesia en actividades educativas, lo que implicaba la introducción de contenidos de moral religiosa en el currículum oficial. Con base en ello, se planteó, por ejemplo, que los contenidos acerca de la educación sexual debían ser tratados en las escuelas públicas de acuerdo con la idiosincrasia de las mayorías, que era el modo de ser propio de los católicos ${ }^{70}$.

Estos planteamientos fundamentaban el modelo educativo basado en los principios de moral sexual católica, tales como la castidad, virginidad y la familia nuclear, unidad básica de la sociedad, integrada por el hombre y la mujer, la indisolubilidad del matrimonio y la imposibilidad de separar la sexualidad del amor conyugal y la procreación ${ }^{71}$. El modelo educativo católico se opone abiertamente al uso de anticonceptivos artificiales, a las técnicas de reproducción asistida, a la legalización de la interrupción voluntaria del embarazo, al reconocimiento de los derechos sexuales y reproductivos de mujeres, minorías sexuales y adolescentes, y a la educación sexual laica. ${ }^{72}$

En el caso mexicano, el Estado asumió formalmente la tarea de impartir la educación sexual a la población en edad escolar desde 1973, tras expedirse la Ley Federal de Educación que reemplazó a la Ley Orgánica de Educación Pública de 1942, lo que fue parte de la promoción de una política demográfica cuyo principal objetivo era reducir la tasa de nacimientos. A partir de ese momento se han implementado diferentes modelos de educación sexual en el nivel básico que privilegian una visión científica del tema.

Sin embargo, es necesario señalar que la emergencia histórica de la laicidad educativa no ha impedido que en la enseñanza de contenidos relacionados con la sexualidad predomine una moral religiosa. Lo cual nos habla de que todavía hay pendientes en la educación pública que recibe la población infantil y

\footnotetext{
${ }^{69}$ Pontificio Consejo para la Familia, "Sexualidad humana: verdad y significado. Orientaciones educativas en familia", Vaticano, 1995, p. 64.

70 S. Loaeza, "La Iglesia y la educación en México", p. 190.

${ }^{71}$ Pontificio Consejo para la Familia, 1995

${ }^{72}$ Es importante señalar que este modelo no responde a realidades sociales específicas, sino que fundamentalmente pretende imponer prescripciones morales. Esto es necesario enfatizarlo pues, además, se ha comprobado que modelos de este tipo no son funcionales en tanto que no cumplen con los objetivos de prevención de enfermedades ni de embarazos de adolescentes y su implementación presenta varios problemas éticos. (Véase John Santelli, et al., "Abstinence-Only-Until-Marriage: An Updated Review of U.S. Policies and Programs and their Impact", Journal of Adolescent Health, núm. 61, Estados Unidos, 2017, pp. 273-280.
} 
adolescente en México ${ }^{73}$. Para que efectivamente sea de carácter laico tal educación, requiere que sea impartirla desde una perspectiva secular, como una forma de garantizar y preservar su carácter científico. De igual modo, la laicidad es una condición necesaria para avanzar en el reconocimiento de los derechos de niños y adolescentes y una vía para la democratización de esta educación en tanto que permite incluir los intereses y demandas de información de estos sectores de la población en los programas oficiales de educación sexual.

\section{Consideraciones finales}

El devenir de los conflictos que se han suscitado entre el Estado mexicano y la Iglesia Católica desde la Reforma liberal hasta nuestros días, dejan ver una relación institucional muy compleja y cambiante entre ambas instancias cuyas implicaciones han definido no sólo el curso de la política en materia religiosa, sino que han repercutido notablemente en el ámbito de la educación pública. El Estado al asumir la tarea educativa y establecer la laicidad como principio rector de sus instituciones modernas desató una querella escolar, una disputa por el control escolar a fin de imponer una visión hegemónica a partir de los contenidos de aprendizaje.

En este artículo intentamos mostrar elementos para comprender las implicaciones de esta relación a partir de la conformación de Estado educador y el papel de la laicidad y el laicismo en la misma; del análisis de las vertientes del discurso laicista que marcan un movimiento singular a lo largo de la historia del México y de las tendencias en el actuar de la Iglesia, en tanto que actor-agente social con posicionamientos estratégicos en la querella educativa. Si bien dicha querella habrá de continuar y quizá se oriente por otros derroteros, es importante no desatender la problemática de la educación sexual dado que es un tema prioritario en la actualidad por las repercusiones que tiene en los ámbitos de la salud pública y los derechos humanos.

En los últimos años se ha dado un avance importante en el reconocimiento de los derechos sexuales y reproductivos de grupos y sectores poblacionales vulnerables como las mujeres, los adolescentes y las personas cuya orientación erótico-afectiva y/o identidad genérica no concuerdan con el paradigma heterosexual. Algunos autores como Roberto Blancarte ${ }^{74}$ sostienen una postura optimista al afirmar que el paulatino reconocimiento de los derechos de estos grupos en la actualidad es uno de los principales impulsores de la laicidad es este país. No obstante, y casi paradójicamente este mismo fenómeno, junto con el progresivo abandono del laicismo, ha propiciado el resurgimiento de grupos conservadores de afiliación religiosa que se oponen a dichos derechos y que pretenden intervenir de manera directa

\footnotetext{
${ }^{73}$ Laura Rangel Bernal, "Educación sexual en escuelas mexicanas: entre el discurso científico laico y la moral religiosa", Revista Palobra, no. 2, vol. 19, Cartagena, 2019, pp. 1-20.

${ }^{74}$ R. Blancarte, Libertad religiosa, Estado Laico y no discriminación.
} 
en la creación de programas de educación sexual de nivel básico con lo cual se reactualiza la querella educativa.

Por ello, es necesario redoblar los esfuerzos para la reivindicación del laicismo como racionalidad crítica opuesta a los dogmas y que se alimenta de la pluralidad-tolerancia opuestas al monopolio de la verdad. Frente a la actual ofensiva educativa de la Iglesia y otros grupos caracterizados como de derecha política, lo que podríamos considerar una nueva reconquista cultural, empresa que emprendió el papado desde hace varias décadas, y cuyas manifestaciones más visibles son la privatización de la educación particularmente la de corte religiosa- y la intervención directa en temas vinculados con la sexualidad. Se requiere, en suma, implementar con mayor énfasis acciones en favor de la educación laica, como instrumento jurídico de convivencia plural, así como reivindicar la vigencia del Estado educador, capaz de hacer frente a los cambios culturales por venir.

\section{Bibliografía}

\section{Fuentes primarias}

Gobierno de México, Constitución Política de los Estado Unidos Mexicanos, México, Diario Oficial de la Nación, 1917.en http://www.ordenjuridico.gob.mx/Constitucion/1917.pdf (consulta: 21 de enero de 2019).

Gobierno de México, "Decreto que reforma al Artículo 3", 1934. En https://www.insp.mx/transparencia/XIV/leyes federales/refcns/pdfsrcs/3.pdf (consulta: 17 de enero de 2019).

Gobierno de México, Ley Orgánica de la Educación Pública Reglamentaria de los Artículos $3^{\circ}$, 31, Fracción I; 73 Fracciones X y XXI; y 123, Fracción XII de la Constitución Política de los Estados Unidos Mexicanos, México, Diario Oficial de la Nación, 1942.

\section{Fuentes secundarias}

Barranco, Bernardo, "La clase política mexicana una amenaza para la laicidad", Blog Cuaderno de bitácora, 2015, en https://bernardobarranco.wordpress.com/2015/11/19/la-clase-politica-mexicanauna-amenaza-para-la-laicidad/ (consulta: 2 de marzo de 2019).

Bazant, Mílada, Historia de la educación durante el Porfiriato, México, El Colegio de México, 1993.

Blancarte Pimentel, Roberto, Libertad religiosa, Estado Laico y no discriminación, México, Consejo Nacional para Prevenir la Discriminación, 2008.

Contreras Betancourt, Leonel, "Juárez y la instrucción pública al triunfo de los liberales", Digesto documental de Zacatecas, vol. IV, núm. 7, México, 2006, pp. $161-168$. 
Ducoing Watty, Patricia, "Rébsamen: algunas aportaciones conceptuales al proyecto modernizador de la educación en México", Perfiles Educativos, vol. XXXV, núm. 140, México, 2013, pp. 149-168.

Durkheim, Emile, Las reglas del método sociológico, Madrid, Morata, 1974.

Curley, Robert, "Los laicos, la Democracia Cristiana y la Revolución mexicana, 1911-1926”, Signos históricos, núm. 7, México, 2001, pp. 149-170.

Galván, Luz Elena, El proyecto de Educación Pública de José Vasconcelos. Una larga labor de intentos reformadores, México, Centro de Investigaciones y Estudios Superiores de Antropología Social, 1982.

González, María del Refugio, Las relaciones entre el Estado y la Iglesia en México, México, Cámara de Diputados, LV Legislatura, Instituto de Investigaciones Legislativas, 1992 , https://archivos.juridicas.unam.mx/www/bjv/libros/2/956/16.pdf (consulta: 2 de marzo de 2019).

González Villarreal, Roberto y Arredondo López, Adelina, "1861: la emergencia de la educación laica en México”, Historia Caribe, vol. XII, núm. 30, 2017, pp. 2549.

Gruppi, Luciano, El concepto de hegemonía en Gramsci, México, Ediciones de Cultura Popular, 1978.

Grupo de Información en Reproducción Elegida, "En salud, el oscurantismo mata", 2007, en http://repositorio.gire.org.mx/handle/123456789/1841 (consulta: $10 \mathrm{de}$ febrero de 2019).

Hale, Charles A., El liberalismo mexicano en la época de Mora (1821-1853). México, Siglo XXI Editores, 1972.

Hale, Charles A., La transformación del liberalismo en México a fines del siglo XIX, México, Fondo de Cultura Económica, 2002.

Loaeza Tovar, Soledad, Clases medias y política en México: la querella escolar, 1959-1963, México, El Colegio de México, 1988.

Loaeza, Soledad, El fin de la ambigüedad: las relaciones entre la Iglesia y el Estado en México, 19982-1990, México, Instituto de Doctrina Social Cristian, 1990.

Loaeza, Soledad, "La Iglesia y la educación en México. Una historia en episodios", en Gonzalbo Aizpuru, P. (coord.), Historia y Nación I. Historia de la educación y enseñanza de la historia, México, El Colegio de México, 1998, pp. 173-193.

Magallanes Delgado, María del Refugio, La educación laica en México. La enseñanza de la moral práctica XIX-XX, México, Policromía, 2016.

Martínez Assad, Carlos, "Revolución, laicismo y educación”, en Salazar Ugarte, P. y Capdevielle, P. (coords.), Para pensar y entender la laicidad, México, 
Universidad Autónoma de México/Instituto Federal Electoral/Miguel Ángel Porrúa, 2013, pp. 137-182.

Martínez, María Teresa, "Secularización y laicidad: entre las palabras, los contextos y las políticas", Sociedad y Religión, vol. XXI, núm. 36, pp. 66-88. 2011.

Mejía Piñeros, María Concepción, "Cambios recientes en las relaciones IglesiaEstado en México y su impacto en los derechos de las mujeres", en "XX Congreso Internacional de la Latinamerican Studies Association", Guadalajara, 16-20 de abril de 1997, en http://lasa.international.pitt.edu/LASA97/mejia.pdf (consulta: 5 de marzo de 2019).

Meníndez, Rosalía, "Los proyectos educativos del siglo XIX: México y la construcción de la Nación”, Estudios, vol. X, núm. 101, 2012, pp. 191-203.

Monsiváis, Carlos, El Estado laico y sus malquerientes, México, Universidad Autónoma de México/Random House Mondadori, 2008.

Natividad Rueda, Leonardo, Las relaciones Estado-Iglesia(s) en México, 20002013: construcción de la agenda política, México, Movimiento Ciudadano, 2015.

Panizza, Roberta, "El principio de subsidiariedad", 2018, en www.europarl.europa.eu/ftu/pdf/es/FTU_1.2.2.pdf (consulta: 18 de febrero 2019).

Pereda, Carlos, "El laicismo también como actitud", Isonomía, Revista de Teoría y filosofía del Derecho, núm. 24, 2006, pp. 7-23.

Pontificio Consejo para la Familia, "Sexualidad humana: verdad y significado. Orientaciones educativas en familia", Vaticano, 1995 en http://www.vatican.va/roman_curia/pontifical_councils/family/documents/rc_pc family_doc_08121995_human-sexuality_sp.html (consulta: 16 de enero de 2019).

Rangel Bernal, Laura. "Educación sexual en escuelas mexicanas: entre el discurso científico laico y la moral religiosa". Revista Palobra, vol. 19, no. 2, Colombia, 2019, pp. 1-20.

Rivera Castro, Faviola, "Laicidad y pluralismo", Isonomía. Revista de Teoría y Filosofía del Derecho, núm. 33, 2010, pp. 35-64.

Rosas Salas, Sergio Francisco, "De la República católica al Estado laico: Iglesia, Estado y secularización en México, 1824-1914”, Lusitania Sacra, núm. 25, 2012, pp. 227-244, en https://repositorio.ucp.pt/bitstream/10400.14/9838/1/LS_S2_25_SergioRosasSal as.pdf (consulta: 27 febrero de 2019).

Salazar Ugarte, Pedro, La laicidad: antídoto contra la discriminación, México, Consejo Nacional para Prevenir la Discriminación, 2007. 
Santelli, John et al., "Abstinence-Only-Until-Marriage: An Updated Review of U.S. Policies and Programs and their Impact", Journal of Adolescent Health, núm. 61, Estados Unidos, 2017, pp. 273-280.

Tenti Fanfani, Emilio, Sociología de la educación, Buenos Aires, Universidad Nacional de Quilmes, 2004.

Torres Septién Torres, Valentina, La educación privada en México, 1903-1976, México: El Colegio de México/Universidad Iberoamericana, 1997.

Vázquez, Josefina Zoraida, Nacionalismo y educación en México, México, El Colegio de México, 1970.

Velasco Ibarra Argüelles, Enrique, Estado laico mexicano: un ideal deslucido en busca de sentido, México, Instituto de Investigaciones Jurídicas de la Universidad Autónoma de México, 2015.

Villalpando Nava, José Manuel, (2012), Historia de la educación en México, México, Porrúa.

Villaseñor, Guillermo, Estado e Iglesia: el caso de la educación, México, EDICOL, 1978.

Weinamar, Caterine et al., Escuela y la educación sexual, Argentina, Manantial/UNFPA, 2008 